\title{
Medical profession urged to end mental health discrimination
}

\author{
Early released Aug. 19, 2008
}

$\mathrm{D}$ octors are at least as guilty of discriminating against people with mental illnesses as the general population, the chair of the Mental Health Commission of Canada told delegates to the Canadian Medical Association (CMA) annual meeting.

"One of the first targets for our antistigma campaign is health care professionals," former Senator Michael Kirby told an Aug. 18, 2008, special session of the CMA's 141st general council in Montréal. "You'd think that health care workers would be less prejudiced about mental illness than the general population. You would be wrong."

Kirby cited international studies indicating that people with mental illness experience high levels of discrimination from family doctors, psychiatrists and emergency staff, and that mental health professionals are more likely than the general populace to support restrictions on people with mental illness.

At the same time, physicians themselves suffer from high levels of stress and mental illness. A British Columbia study estimated that the annual rate of physician suicide from 1991 to 1998 was notably higher than that of the general population (21.9 per 100000 population, as compared to 13.8 in the general population), Kirby said.

"You cannot help your patients if you are not healthy yourselves," he told delegates attending a session on mental health in Canada.

But physicians tend not to be forthcoming about their own problems. A recent survey (Psychother Psychosom 2007;76:306-10) by the Michigan Psychiatric Society found that half of the psychiatrists surveyed would rather treat themselves secretly than have their mental illness recorded on their medical chart, Kirby said.

About 4000 Canadians commit suicide annually, accounting for more deaths than motor vehicle crashes and AIDS combined, said Dr. Donald Mil- liken, a Victoria, British Columbia, psychiatrist and a panelist at the strategic session. In terms of years of life lost, the toll of mental illness is huge, since deaths typically occur at a younger age, he added.

People with bipolar illness have an average lifespan that is 10 years less than the overall Canadian population, while the average lifespan of those with schizophrenia is two decades less. "And in the last 20 to 30 years, this is getting worse [but is] often hidden because of co-morbidity."

Untreated depression after a heart attack, for example, places patients at higher medical risk than continuing to smoke, while depression is associated with increased insulin resistance among diabetics, said Milliken. He also urged that mental health services receive funding on par with that obtained for the treatment of physical diseases.

Canada's physicians must make a "conscious decision that these [mental] illnesses are medically important and that we will no longer tolerate prejudice and discrimination in our own house against those who suffer," he said. "We cannot persuade other groups to do the same unless we have our own house clearly in order."

Austin Mardon, a mental health advocate who suffers from schizophrenia, told delegates that stigmatization is so rampant than an Alberta family opted to depict one of their own as a drug-addicted murderer rather than publicize his mental illness. "This is the face of stigma, when it is easier to admit your sibling is a crazed killer than to admit he has an illness."

Only "education, education and more education," can fight stigmatization, Mardon said. As medical care and treatments improve, people with mental illness must "find a way to allow ourselves to reintegrate. It is almost as if we have to learn how to forgive ourselves for being ill. My wife says all she expects from me is to live as healthy and happy a life as I am capable of. Now, I have to give myself permission to be content with that."

Evidence of the stigmatization of people with mental illness was also evident in the findings of the CMA's annual National Report Card of Health, which found that $46 \%$ of 1002 Canadians surveyed by Ipsos-Reid believe that mental illness is "an excuse for bad behaviour."

Roughly $61 \%$ of those surveyed were unlikely to seek treatment from a family doctor with a mental illness, while less than half believed that alcohol and drug addiction is a mental illness.

\section{National strategy}

Physician delegates to general council later passed a motion calling on the CMA to work with the Mental Health Commission of Canada to develop a national strategy for mental health. Doctors should play a lead role combatting stigma that prevents people with mental illness from seeking help, argued Dr. Patrick White of Edmonton in support of the motion. "It is time for us to provide leadership."

Council also passed a motion to develop programs to reduce stigmatization "generated within the health care system." Stigma coming from the health care system can jeopardize the ability of patients to take part in society because it can prevent them from accessing services, said Dr. Alain Messier of Bedford, Quebec.

Stigmatization against aboriginal Canadians also surfaced on the agenda in the form of a motion calling on medical schools to tackle negative stereotyping of aboriginal peoples with mental illnesses or substance abuse problems. Doctors need training so they do not stigmatize aboriginals for the multiple issues they may experience in addition to their "stigmatization just for being aboriginal," said Dr. Cynthia Orlaw, president of the Northwest Territories 
Medical Association. Orlaw said colonization and residential school syndrome have contributed to the situation where the suicide rate among Aboriginal people is five to six times higher than that in the general population.

Delegates also passed motions calling on the CMA to: develop a five-year plan to improve access to psychiatric care and reduce stigma; work with governments to introduce mental health programs and mental health screening in schools; establish benchmarks for access to psychiatric care and treatment in rural and remote areas; and call on governments to improve coordination of mental health services for children. Children typically wait between 8 and 18 months for psychiatric consultations, noted Dr. Kathryn Bigsby of Charlottetown, Prince Edward Island.

Doctors must also "accept and have the courage to take care of ourselves as physicians," said Dr. Jean-Bernard Trudeau, president of the Quebec Medical Association, who noted that $37 \%$ of doctors go through a depressive episode while in training. To that end, the CMA was urged to develop a strategy to support the mental health of Canada's doctors. - Ann Silversides, CMAJ

CMAJ 2009. DOI:10.1503/cmaj.081304 